\title{
Comparative Analysis of Gas Emissions from a Vehicle Running on Ethanol and Natural Gas Fuel
}

\author{
Raphael Araújo de Holanda, Gil Colona Laranja, Cleiton Rubens Formiga Barbosa, Francisco de Assis Oliveira \\ Fontes and Cleiton Rubens Formiga Barbosa Junior \\ Department of Mechanical Engineering, Federal University of Rio Grande do Norte, Natal/RN 59072-970, Brazil
}

Received: March 21, 2014 / Accepted: April 08, 2014 / Published: July 25, 2014.

\begin{abstract}
It is known that the transport sector has a fundamental importance in the modern society, as the economic development is directly linked to mobility. Over the years, the transport became linked to different environmental problems, which can be detached greenhouse gases emissions in the atmosphere, where in recent decades can be perceived the intensification and targeting of efforts in research and development of new technologies to reduce the levels of greenhouse gases emissions in the atmosphere. In this context, it can be highlighted the modern systems of electronic engine management, new automotive catalysts and the use of renewable fuels which contribute to reducing the environmental impact. This research had, as its purpose, the analysis of fuels characteristics used for testing, comparative analysis of gas emissions from a motor vehicle running on ethanol or natural gas fuels according to NBR 6601 and conducting tests to estimate the maximum catalytic efficiency. For the implementation of trial, a flex vehicle was installed in a chassis dynamometer equipped with a gas analyzer, in order that before the completion of the urban driving cycle, were determined the content of hydrocarbons corrected, carbon monoxide corrected, carbon dioxide and oxygen present in gas emissions from the engine. The research concluded that: the performance analysis for characterization of fuel showed consistent with ANP specifications; after tests performances, it can be stated that natural gas fuel was the fuel which had the highest content of hydrocarbons and carbon monoxide corrected, while ethanol had the highest amount of carbon dioxide and oxygen residue present in gas emissions; before a comparative analysis, the vehicle catalyst showed the best performance for reducing the content of hydrocarbon corrected present in exhaustion gases when it worked with natural gas fuel and showed maximum efficiency of $100 \%$ to reduce the content of carbon monoxide corrected for both fuels. Before this, it can be stated that the vehicle catalyst showed satisfactory performance, achieving good reduction levels of greenhouse gases emissions.
\end{abstract}

Key words: Gas emissions, ethanol, natural gas fuel, NBR 6601, catalytic efficiency.

\section{Introduction}

It is well known that a long time ago, the transport sector has a fundamental importance in the global society, as economic development is directly related to the mobility of people and merchandises, and vehicles the means of locomotion most used until today. Over the time, there was an increase of the number of vehicles circulating daily in the world and therefore, the growth in greenhouse emissions released into atmosphere, as the result of the combustion process

Corresponding author: Raphael Araújo de Holanda, master, research fields: environmental emissions, renewable energy, thermal engineering and thermodynamics. E-mail: raphaelholanda@hotmail.com. inside the motor vehicle [1]. At the same time of this scenario, it is observed, in recent decades, the search for improvements to answer these requirements, leading the intensification of efforts in research and development of new technologies, which will promote the reduction of emission levels of greenhouse gases in the atmosphere. In this context, it can highlight the modern systems of electronic engine management, new automotive catalysts and the use of renewable fuels that contributes to reducing emission levels of greenhouse gases into atmosphere [2]. This part is consolidated with the increasing discovery of many renewable fuels, considered clean fuels [3]. Some time ago, the vehicles are being equipped with devices that 
allow them to use different types of fuels to promote a greater economy and a reducing of emission levels coming from internal combustion process in engines, as a way to attend the legislation requirements and therefore t0 preserve the environment.

This research aims to perform the analysis of both of the ethanol and physicochemical characterizations of natural gas fuel. We also aim to perform comparative analysis of the gas emissions of a flex vehicle to urban cycle in a chassis dynamometer, running on ethanol or natural gas fuels to estimate the maximum efficiency of the automotive catalyst operating with different fuels.

This paper is organized as follows: Section 2 addresses the development; Section 3 presents the results and discussion; and Section 4 brings the conclusions.

\section{Development}

\subsection{Vehicle Used in the Tests}

The vehicle used to perform the route of the driving in urban traffic is a lightweight self-propelled road vehicle, engine 1.4, Flex model.

\subsection{Gas Analyzer}

The gas analyzer applied to the tests was used to determine the concentrations of hydrocarbons, carbon monoxide, carbon dioxide and oxygen through the electrochemical cell. The exhaust gas samples were collected in real time with the support of the probe for aspiration of gases, to determine the concentrations in emission test, data was collected after and before the catalyst for maximum catalytic efficiency test.

\subsection{Ethanol}

The analysis of ethanol total characterization had the physical structure of the Fuels and LCL-UFRN (Lubricants Laboratory of Federal University of Rio Grande do Norte).

\subsection{Natural Gas Fuel}

The completion of physical-chemical characterization analysis of natural gas fuel had the physical structure of the LQG-CTGÁS-ER (Quality Laboratory of Gas of Technology Center Gas and Renewable Energy).

\subsection{Test Procedure Emissions}

It was elaborated a procedure for conducting the emissions testing under simulated conditions of normal use average in urban traffic based on the guidelines of NBR 6601, which prescribes the method for the determination of hydrocarbons, carbon monoxide, carbon dioxide, emitted by the engine through the discharge tube of a road vehicle propelled lightweight. The emissions test consists basically in determining concentrations of hydrocarbons, carbon monoxide and carbon dioxide from the collection of emissions with the gas analyzer, while the vehicle performs a path coordinates of pre-established driving cycles, for such being necessary to use the chassis dynamometer to simulate shooting actual conditions in runway. The emission test cycle in urban chassis dynamometer consists of two distinct parts: cold start and warm start, with a break of $10 \pm 1$ min between them [4].

Elaborate procedure for conducting the tests: achievement test for determining emissions of hydrocarbons, carbon monoxide, carbon dioxide and oxygen in a Flex model vehicle, using driving cycles developed in chassis dynamometer, which simulates vehicle in urban traffic using the fuel ethanol and natural gas fuel, for such the dynamometer had to be fed with the following variables:

- Equivalent inertia corresponding to the total weight of the vehicle: $1,304 \mathrm{~kg}$;

- Aerodynamic drag of the vehicle that is: $4.5 \mathrm{~kW}$;

- Resistive power of chassis dynamometer which is: $0.3 \mathrm{~kW}$.

\subsubsection{Cold Start}

The cold start cycle requires 1,371 s (22 min and 51 s) to be fully invested being traversed a distance of approximately $12.1 \mathrm{~km}$, this cycle is divided into two phases. The first phase, representing the phase "transient" of cold start, which has a duration of $505 \mathrm{~s}$ 
(8 $\mathrm{min}$ and $25 \mathrm{~s}$ ) and being traversed a distance of approximately $5.78 \mathrm{~km}$. The second phase, representing the phase "stabilized", is the conclusion of the test cycle, which has a duration of 866 s (14 min and $26 \mathrm{~s}$ ), which is traversed a distance of approximately $6.32 \mathrm{~km}$, ending with the engine shutdown.

\subsubsection{Warm Start}

Similarly, the cycle of warm start is divided into two phases. The first phase, representing the phase "transient" from the warm start, which has a duration of $505 \mathrm{~s}$ (8 min and $25 \mathrm{~s}$ ) and traversed a distance of approximately $5.78 \mathrm{~km}$, while the second phase of the warm start cycle, representing the phase "stabilized" is identical to the second phase of the cycle cold start, therefore, the test is not run, but considering the values obtained in stabilized cold start phase.

\subsubsection{Coordinates of Urban Driving Cycle}

The driving cycle on chassis dynamometer, to simulate driving conditions in urban areas, is defined by a continuous graph of speed versus time. It consists of not repeated sequences of slow running system, acceleration, cruising speeds and decelerations in magnitudes and varied combinations. The coordinates of this driving cycle (Fig. 1) are specified in Table 1 of Annex B of NBR 6601 [4].

\subsubsection{Adequation of Urban Cycle Coordinates}

To be performed the route proposed by NBR 6601, an adjustment of the coordinates (Fig. 2) was made, according to the margin of tolerance on speed limits, which are allowed by this standard [5].

\section{Results and Discussion}

Following are the results of total characterization analysis of the ethanol in the LCL-UFRN and physicochemical characterization of natural gas fuel in LQG-CTGÁS-ER. Also shown are the results of tests conducted in LMA-CTGÁS-ER, where emissions were registered during the performance of urban cycle. These results are shown in graphics that illustrate the behavior of the quantities involved in this study: the contents of carbon monoxide corrected, hydrocarbons

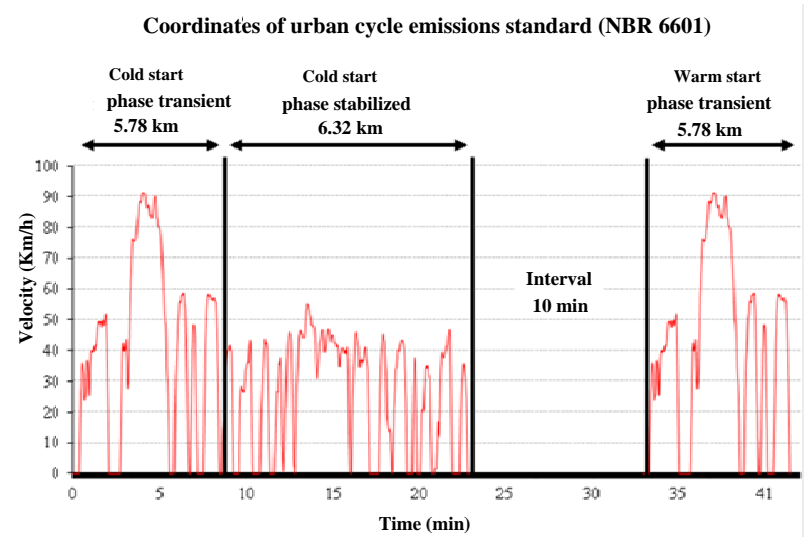

Fig. 1 Graphic coordinates of urban emissions standard (NBR 6601).

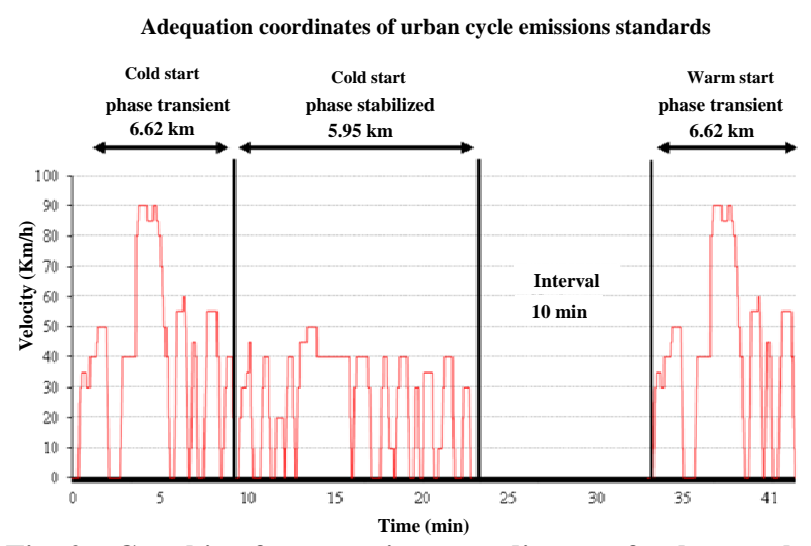

Fig. 2 Graphic of appropriate coordinates of urban cycle emissions standards.

corrected, carbon dioxide and oxygen for each of the fuels used. It is still shown, by way of knowledge, the results obtained for maximum catalytic efficiency in a given moment, when the catalyst is submitted to operation with each of the fuels used.

\subsection{Results Obtained from the Analysis of Fuels Used}

The completion of the total characterization analysis of the ethanol used in this work was supported by technical group and physical infrastructure of LCL-UFRN. The result of the characterization analysis of ethanol is in compliance with ANP specifications and their results are shown in Table 1.

The completion of the analysis of physical-chemical characterization of natural gas fuel used in this work, had the support of the technical group and physical infrastructure of the LQG-CTGÁS-ER. The result of analysis of physicochemical characterization of 
natural gas fuel is in compliance with ANP specifications and their results are shown in Table 2.

\subsection{Conducting Tests of Urban Cycle}

To perform the test driving cycle of urban traffic, it was necessary to make adaptations in the guidelines of the NBR 6601, these adjustments were made taking into account the velocity margin of tolerance which is permitted by rule, to make possible the achievement of compliance coordinates of urban cycle [5]. The tests for determining emissions were performed in accordance with the standard, which sets out the methodology for the simulation of driving a vehicle in urban traffic in chassis dynamometer using coordinates of speed versus time [6].

Sections 3.2.1-3.2.4 show the results of fixed hydrocarbon levels, carbon monoxide, corrected, carbon dioxide and oxygen residual, all present in the emissions from the combustion of ethanol and natural gas fuels, during the driving cycle urban traffic.

\subsubsection{Result of Corrected Hydrocarbon Content}

From the results obtained in the analysis of exhaust

Table 1 Result of ethanol analysis.

\begin{tabular}{ll}
\hline Technical features & Ethanol \\
\hline Aspect & Clear and free of impurities \\
Color & Colorless \\
Specific mass $\left(\mathrm{kg} / \mathrm{m}^{3}\right)^{(1)}$ & 809.1 \\
Alcoholic content $\left({ }^{\circ} \mathrm{INPM}\right)$ & 93.2 \\
Electrical conductivity $(\mu \mathrm{S} / \mathrm{m})$ & 190 \\
Hydrogen potential $(\mathrm{pH})$ & 7.2 \\
\hline
\end{tabular}

${ }^{(1)}$ measured at $20^{\circ} \mathrm{C}$.

Table 2 Result of natural gas fuel analysis.

\begin{tabular}{ll}
\hline Technical features & Natural gas fuel \\
\hline Superior calorific value $\left(\mathrm{kJ} / \mathrm{m}^{3}\right)$ & 38,180 \\
Wobbe index $\left(\mathrm{kJ} / \mathrm{m}^{3}\right)$ & 48,750 \\
Mehtane $(\% \mathrm{~mol} / \mathrm{mol})$ & 90.030 \\
Ethane $(\% \mathrm{~mol} / \mathrm{mol})$ & 5.725 \\
Propane $(\% \mathrm{~mol} / \mathrm{mol})$ & 0.700 \\
Butane and heavier $(\% \mathrm{~mol} / \mathrm{mol})$ & 0.293 \\
Inert $\left(\mathrm{N}_{2}+\mathrm{CO}_{2}\right)(\% \mathrm{~mol} / \mathrm{mol})$ & 3.253 \\
Nitrogen $(\% \mathrm{~mol} / \mathrm{mol})$ & 2.261 \\
Relative density & 0.613 \\
Specific mass $\left(\mathrm{kg} / \mathrm{m}^{3}\right)^{(1)}$ & 0.739 \\
\hline
\end{tabular}

${ }^{(1)}$ measured at $20^{\circ} \mathrm{C}$. gases during the testing of emissions driving in urban cycle traffic with flexible-fuel vehicles running on ethanol or natural gas fuel, it was performed a comparative analysis of the average amount of corrected hydrocarbon content present in these gas emissions (Fig. 3). The fuel which generated the highest average corrected of hydrocarbon content present in gas emissions was natural gas fuel.

\subsubsection{Result for the Content of Carbon Monoxide}

\section{Corrected}

From the results obtained of exhaust gases analysis during the testing of emissions driving in urban cycle traffic with flexible-fuel vehicles running on ethanol or natural gas fuel, it was performed a comparative analysis of the average content of carbon monoxide corrected present in these gas emissions (Fig. 4). The fuel that generated the highest average of corrected carbon monoxide content present in gas emissions was natural gas fuel.

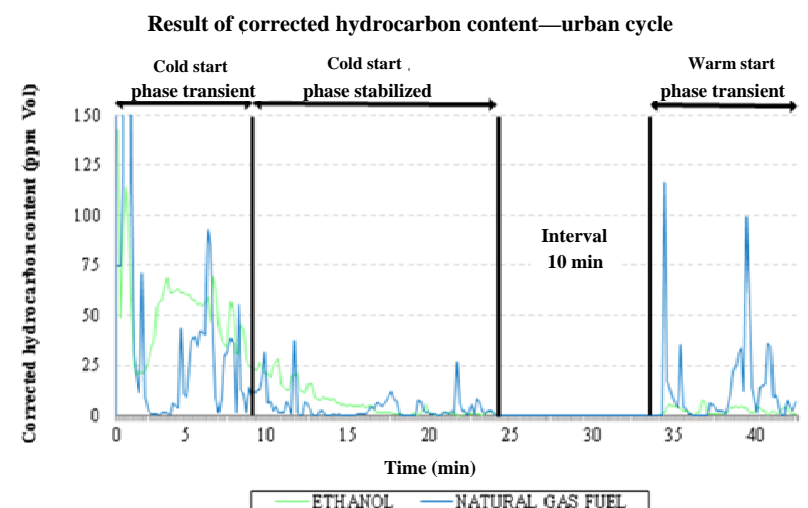

Fig. 3 Graphic with the results of the analysis of corrected hydrocarbon content.

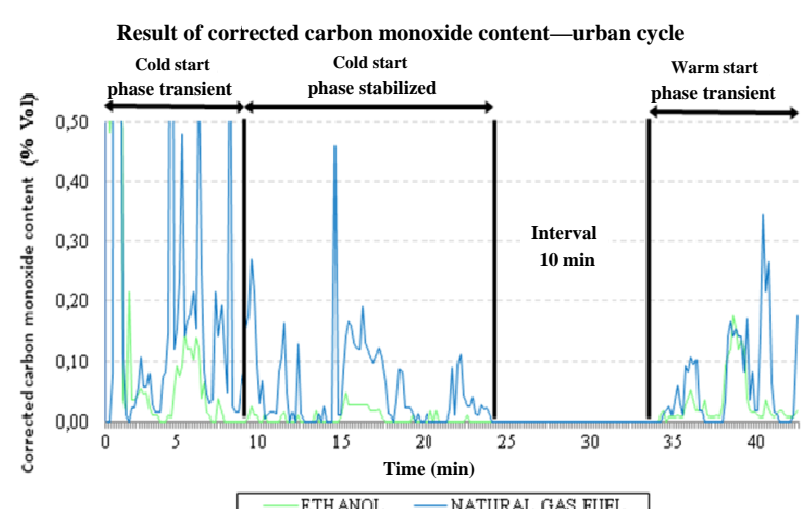

Fig. 4 Graphic with the results of the analysis of corrected carbon monoxide content. 


\subsubsection{Result for the Content of Carbon Dioxide}

From the results obtained of exhaust gas analysis during test emissions driving in urban cycle traffic with flexible-fuel vehicles running on ethanol or natural gas fuel, it was performed a comparative analysis of the average of carbon dioxide content present in these gas emissions (Fig. 5). The fuel which generated the highest average content of carbon dioxide present in gas emissions was ethanol.

\subsubsection{Result of the Oxygen Content}

From the results obtained of exhaust gas analysis during test emissions driving in urban cycle traffic with flexible-fuel vehicles running on ethanol or natural gas fuel, it was performed a comparative analysis of the average oxygen content present in these gas emissions (Fig. 6). The fuel which generated the highest average content of oxygen present in gas emissions was ethanol.

\subsection{Results for Maximum Catalytic Efficiency}

By way of knowledge, it was performed a comparative analysis in a given time for gas emissions collected before and after the catalyst of the vehicle, which resulted in the maximum catalytic efficiency of the catalyst used, the analysis of test results when the vehicle is submitted to operation in slow running with each one of the fuels used are shown in Table 3.

From the point measurements of the exhaust gases before and after the catalyst, an estimate of the maximum efficiency catalytic operating with ethanol or natural gas fuel was calculated, showing the

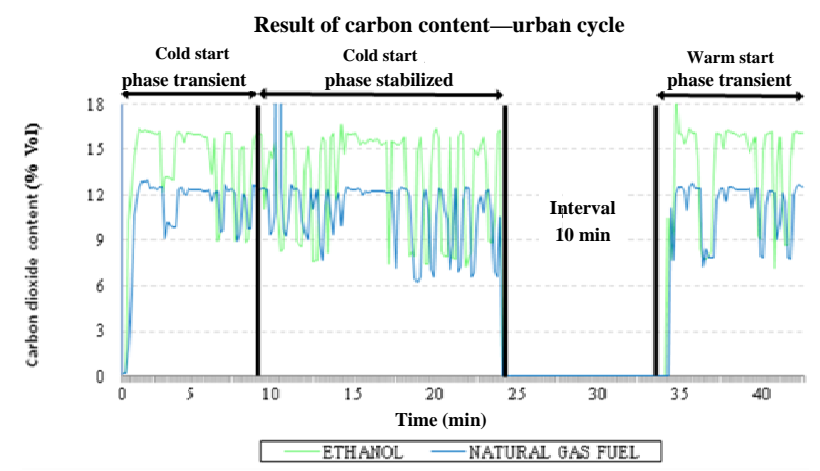

Fig. 5 Graphic with the results of the analysis of carbon dioxide content.

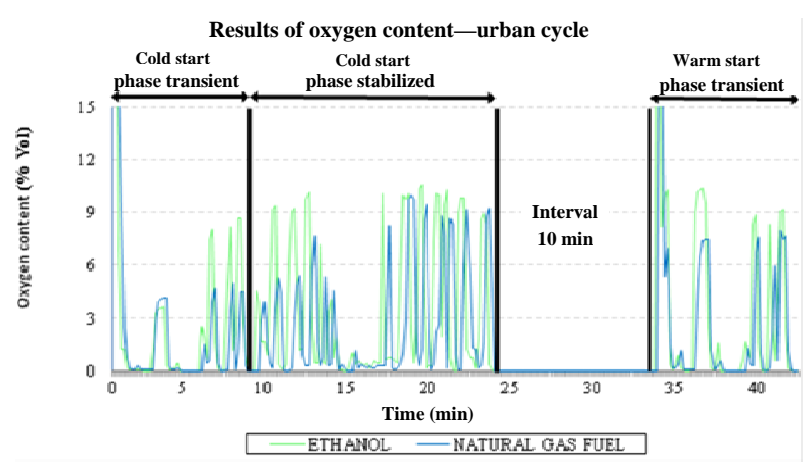

Fig. 6 Graphic with the results of the analysis of oxygen content.

Table 3 Results of maximum catalytic efficiencies at a glance.

\begin{tabular}{lll}
\hline Fuel & $\begin{array}{l}\text { Corrected } \\
\text { hydrocarbon } \\
\text { content (\%) }\end{array}$ & $\begin{array}{l}\text { Corrected carbon } \\
\text { monoxide (\%) }\end{array}$ \\
\hline Ethanol & 47 & 100 \\
Natural gas fuel & 76 & 100 \\
\hline
\end{tabular}

best catalytic efficiency for reducing of corrected hydrocarbon content present in exhaust gases when the vehicle ran on ethanol. To reduce concentrations of corrected carbon monoxide, the efficiency was $100 \%$ and equal for both fuels.

\section{Conclusions}

The values obtained for characterization analysis of the ethanol, held at LCL-UFRN, was consistent with the specifications of National Petroleum, Natural Gas and Biofuels Agency (ANP).

The values obtained for analysis of physico-chemical characterization of natural gas, held in LQG-CTGAS-ER, was consistent with ANP specifications.

The experimental methodology adopted in test emissions attended the proposed objectives, making possible the achievement of conclusive results about emissions levels of the vehicle running on different fuels.

The results obtained from the emissions recorded during the performance of urban cycle route, presented in a comparative analysis that: the average of corrected hydrocarbon and corrected carbon monoxide levels, were the biggest natural gas fuel, the 
average content carbon dioxide and oxygen content were highest to ethanol.

The automotive catalyst showed the best maximum catalytic efficiency for reduction of corrected hydrocarbon content when the vehicle ran on natural gas fuel. The result for reduction of corrected carbon monoxide content was $100 \%$ for both fuels.

\section{References}

[1] Degobert, P. 1995. Automobiles and Pollution. France: Institut Français du Pétrole Publications.

[2] Nevers, N. 2000, Air Pollution Control Engineering. 2nd edition. New York: McGraw-Hill.

[3] Bata, M. R. 1994. Alternate Fuels, a Decade of Success and Promise. Morgantown: West Virginia University.

[4] ABNT (Associacao Brasileira De Normas Tecnicas).
2005. Light Road Vehicles and Determination of Hydrocarbons, Carbon Monoxide, Oxides of Nitrogen, Carbon Dioxide and Particulate Matter in the Exhaust Gas. NBR 6601 Standard. Brazil: Brazilian Association of Technical Standards.

[5] Holanda, R. A. 2010. "Analysis of Gaseous Emissions from a Vehicle Flex Running with Different Fuels.” master dissertation, State University Rio Grande do Norte.

[6] Jacondino, G. B. 2005. "Quantification of Vehicle Emissions through the Use of Traffic Simulators.” master dissertation, University of Rio Grande do Sul.

[7] Holanda, R. A., Laranja, G. C., Barbosa, C. R. F., Fontes, F. A. O., and Junior, C. R. F. B. 2013. "Comparative Analysis of Gas Emissions from a Vehicle Running on Ethanol and Compressed Natural Gas.” Presented at the 22nd International Congress of Mechanical Engineering, Ribeirão Preto, SP. 